\title{
LA LARGA SOMBRA DE LAS CATEGORÍAS ACUSATORIO-INQUISITIVO
}

\author{
Máximo Langer ${ }^{1}$
}

\section{Resumen}

Este trabajo argumenta que las categorías acusatorio e inquisitivo han sido más centrales para el derecho procesal penal comparado que lo que se ha reconocido previamente ya que han contribuido a constituirlo y a moldearlo como campo transnacional al reflejar y restringir sus principales tendencias teóricas y sus mayores temas de interés. Se identifican las principales tradiciones teóricas de este campo mediante un relevamiento de los usos que la doctrina y la jurisprudencia le han dado a la distinción entre acusatorio e inquisitivo, y se argumenta que incluso los principales análisis alternativos existentes operan dentro de estas mismas tradiciones teóricas. Además, se aduce que la dicotomía acusatorio-inquisitivo también ha contribuido a limitar el tipo de temas tratados por este campo. Finalmente, se esbozan diversas maneras mediante las cuales el derecho procesal penal comparado puede superar la

\footnotetext{
Profesor de Derecho (tenured Professor of Law), Facultad de Derecho de la Universidad de California, Los Ángeles; abogado, Universidad de Buenos Aires; doctor en Ciencias Jurídicas (S. J. D.), Facultad de Derecho de la Universidad de Harvard. Agradezco a Rachel Barkow, Alejandro Chehtman, Mirjan Damaška, Sharon Dolovich, Jeff Fagan, Malcolm Feeley, James Forman, David Garland, Bernard Harcourt, John Jackson, Josh Kleinfeld, Niki Lacey, Corinna Lain, Inga Markovits, Tracey Mears, Daniel Pastor, Intisar Rabb, Dan Richman, Paul Roberts, David Sklansky, Göran Sluiter, Máximo Sozzo, Carol Steiker, Jordan Steiker, Sergey Vasiliev, Jim Whitman y participantes en seminarios en la Universidad de Amsterdam, Universidad de Buenos Aires, Universidad de Harvard, Universidad de San Andrés, Universidad Metodista del Sur (SMU), Universidad Nacional de Rosario, Universidad Nacional del Litoral, y Universidad Torcuato Di Tella, por sus comentarios sobre borradores anteriores de este trabajo; a David Heyrani por su asistencia en la investigación; a Elyse Meyers por su trabajo editorial; y a Lucas Tassara por su traducción del inglés al español. La versión original en inglés está siendo publicada en Markus D. Dubber \& Tatjana Höernle (compiladores), Handbook on criminal law (Oxford University Press, 2014, en prensa). Esta traducción al español ha sido publicada en la Revista de Derecho Público Nro. 32 (2014) de la Universidad de los Andes, Colombia.
} 
larga sombra teórica y temática de las categorías acusatorio-inquisitivo y así expandir y enriquecer nuestro conocimiento y análisis, tanto positivos como normativos, sobre el proceso penal.

Palabras claves: acusatorio, inquisitivo, sistema acusatorio, sistema inquisitivo, proceso penal, proceso penal comparado, derecho comparado, reforma judicial.

\begin{abstract}
This chapter maintains that the adversarial and inquisitorial categories have been more central to comparative criminal procedure than it has been previously acknowledged because they have contributed to constitute it as a transnational field by reflecting and restricting its main theoretical trends and thematic interests. The article identifyies the main theoretical traditions of this field by mapping commentators' and courts' uses of the adversarial and inquisitorial distinction, and shows that even the main comparative criminal procedure alternative approaches are operating within these same theoretical traditions. The article suggests that the adversarial-inquisitorial dichotomy has also contributed to limit the type of themes that the field has covered. Finally, the article sketches a number of ways in which comparative criminal procedure may transcend the long theoretical and thematic shadow of the adversarial and inquisitorial categories and thus expand the type of positive and normative insights it can bring to our understanding of the criminal process.
\end{abstract}

Keywords: adversarial, inquisitorial, adversary system, inquisitorial system, criminal procedure, comparative criminal procedure, comparative law, judicial reform.

\title{
Introducción
}

Es un lugar común afirmar que lo "acusatorio" y lo "inquisitivo" han sido categorías centrales en el estudio comparado de los procesos penales. En este trabajo sostendré que la influencia y centralidad de estas categorías van todavía más allá de lo que se ha reconocido, ya que ellas han contribuido a constituir y a moldear al derecho procesal penal comparado como campo transnacional de pensamiento, estudio y políticas públicas al reflejar y restringir sus principales tendencias teóricas y sus mayores temas de interés.

De hecho, argumentaré que se pueden identificar las principales tradiciones teóricas dentro de las cuales ha trabajado el derecho procesal penal comparado, mediante un relevamiento de los usos que la doctrina y la jurisprudencia le han dado a la distinción entre acusatorio e inquisitivo. Este relevamiento mostrará cinco usos principales de 
estas categorías, a saber como: (1) tipos ideales-descriptivos; (2) sistemas históricos o sociológicos que se encuentran presentes en procesos penales concretos pasados o contemporâneos; (3) intereses o valores contrapuestas que coexisten en todo proceso penal; (4) funciones del proceso penal; y (5) modelos normativos. Luego de efectuar este relevamiento, afirmaré que incluso los principales análisis del derecho procesal penal comparado que han usado términos o herramientas conceptuales alternativas a la oposición acusatorio-inquisitivo operan dentro de estas mismas tradiciones teóricas.

Además, sustentaré que la dicotomía acusatorio-inquisitivo también ha contribuido a limitar el tipo de temas o cuestiones tratados por el derecho procesal penal comparado, ya que estos estudios han tendido a focalizarse en las características del proceso penal que sobresalen o son resaltadas cuando se yuxtaponen los sistemas acusatorios e inquisitivos, en detrimento de otros temas posibles. La centralidad de esta yuxtaposición ayuda a explicar por qué el derecho procesal penal comparado se ha focalizado principalmente en los procesos penales de los países desarrollados de Occidente, en la persecución local y no transnacional del delito, en el análisis de las instituciones y los roles de los actores del proceso penal, y en el análisis de solo un subconjunto de instituciones y actores de la justicia penal.

Finalmente, señalaré que para que el derecho procesal penal comparado pueda ampliar y profundizar su conocimiento y perspectivas es necesario que supere la larga sombra teórica y temática de las categorías acusatorio-inquisitivo. Aquí esbozaré diversas maneras mediante las cuales el derecho procesal penal comparado puede superar dicha sombra y así expandir y enriquecer nuestro conocimiento y análisis, tanto positivos como normativos, sobre el proceso penal.

Antes de proceder con mi análisis es necesario realizar tres aclaraciones. En primer lugar, incluyo dentro del campo del derecho procesal penal comparado al campo académico que tiene representates en muchas facultades de derecho y otros departamentos universitarios del mundo que estudia al proceso penal desde una perspectiva comparada. Los participantes en este campo son académicos que enseñan o escriben sobre el proceso penal y que, explícita o implícitamente, incluyen un análisis de dos o más jurisdicciones en sus clases o estudios. Estos académicos se ven a sí mismos o son vistos por otros como comparativistas del proceso penal. Pero el derecho procesal penal comparado como campo de pensamiento y de políticas públicas va más de la academia e incluye reformadores legales, jueces, abogados, y diseñadores de políticas públicas que, explícita o implícitamente, comparan dos o más jurisdicciones cuando piensan, analizan, juzgan o intentar reformar el proceso penal.

En segundo lugar, mi argumento sobre la centralidad e influencia de las categorías acusatorio-inquisitivo sobre el derecho procesal penal comparado no es un argumento causal univariable. Hay muchos factores que han constituido y moldeado a este campo de estudio y de políticas públicas que no puedo analizar aquí. Mi argumento es que las categorías acusatorio e inquisitivo han sido uno de los factores que ha jugado un rol importante en la constitución y delimitación de este campo. 
En tercer lugar, las categorías acusatorio e inquisitivo y las formas de pensamiento que ellas reflejan han contribuido a limitar el alcance del derecho procesal comparado de múltiples maneras. Aunque no puedo desarrollar estas ideas aquí por limitaciones de espacio, mi argumento es que, en ciertos casos, las categorías han contribuido a cegar a los participantes del campo del derecho procesal penal comparado. En otras palabras, las categorías han contribuido a invisibilizar otras corrientes teóricas y temáticas que podrían ser utilizadas para analizar el proceso penal desde una perspectiva comparada. Las categorías también han contribuido a excluir o a marginalizar de este campo a un número de académicos y de otros actores legales que podrían ser incluidos o podrían ser centrales para este campo, si el campo estuviera constituido de modo diferente. En otros casos, la centralidad de estas categorías y las corrientes teóricas que ellas reflejan han contribuido a oscurecer o empobrecer el análisis comparado del proceso penal. Finalmente, la centralidad de estas categorías y formas de pensamiento han sido una distracción para ciertos partipantes en el campo del derecho procesal penal comparado, ya que los han incentivado a utilizar ciertas corrientes teóricas y a analizar ciertos temas en desmedro de otros. Estas cuatro formas de influencia sobreel campo del derecho procesal penal comparado han estado presentes individualmente o combinadas en diferentes contextos, dependiendo de las características de actores legales específicos y de los marcos y prácticas institucionales dentro de las cuales estos actores operan.

\section{BREVES ANTECEDENTES HISTÓRICOS}

Los términos acusatorio e inquisitivo tienen una larga historia en el proceso penal. Ya en los siglos XII y XIII la doctrina y otras fuentes legales distinguían entre proceso inquisitivo y acusatorio. En el primero de ellos, los funcionarios públicos podían iniciar un proceso por su propia iniciativa con base en la existencia de rumores públicos (fama). Por el contrario, un proceso acusatorio exigía una acusación por parte de un individuo particular. La distinción entre estos dos tipos de procesos se daba al interior de los sistemas jurídicos no entre diversos sistemas jurídicos. ${ }^{2}$ En otras palabras, los términos eran utilizados principalmente para referirse a dos tipos de procesos que coexistían dentro del mismo sistema jurídico, mas que como herramientas para comparar y distinguir entre procesos legales de distintos sistemas jurídicos. Además, los procesos acusatorio e inquisitivo no connotaban, respectivamente, las jurisdicciones anglosajonas y continental-europeas. ${ }^{3}$

\footnotetext{
2 Aunque se han realizado numerosos estudios históricos sobre los procesos acusatorios e inquisitivos, la historia intelectual y teórica de las categorías acusatorio-inquisitivo aún debe escribirse. Actualmente me encuentro en una etapa temprana del desarrollo de dicho proyecto de investigación. Por lo tanto, la afirmación que hago en el texto sobre el uso de las categorías en los siglos XII y XIII, así como otras que formulo en el resto de este apartado histórico son meramente tentativas y preliminares, puesto que todavía no las he podido corroborar de modo exhaustivo.

3 Para un examen reciente de los principales trabajos sobre el proceso por parte de juristas medievales y de principios de la Edad Moderna, incluyendo sus análisis de los procesos acusatorio e inquisitivo, ver Pennington (2014).
} 
El uso de los términos acusatorio e inquisitivo con fines comparativos surgió como un desarrollo posterior, entre la segunda mitad del siglo XVIII y la primera mitad del siglo XIX. Durante el siglo XVIII, la doctrina y las autoridades políticas en Europa continental, buscando alternativas al proceso penal del Antiguo Régimen, se empezaron a interesar en el procedimiento penal inglés como un posible modelo de reforma. ${ }^{4} \mathrm{La}$ doctrina y las autoridades europeas comenzaron a utilizar la categoría acusatorio para aludir al proceso penal anglosajón, y el término inquisitivo para aludir al proceso penal del Antiguo Régimen o de la Europa continental de ese momento. ${ }^{5}$ Con posterioridad, las jurisdicciones anglosajonas empezaron a utilizar el término adversarial de un modo similar a acusatorio. ${ }^{6}$

El contenido que la doctrina les dio a estas categorías fue variado. En algunas formulaciones, el proceso acusatorio se basaba en la existencia de individuos particulares para la persecución del delito, mientras que en el proceso inquisitivo la persecución penal estaba a cargo de funcionarios públicos. ${ }^{7}$ Otras formulaciones incluían una mayor variedad de características. Por ejemplo, el sistema acusatorio era definido como un proceso penal controlado por las partes, en donde el tribunal era un árbitro pasivo. El proceso acusatorio no procuraba obtener la confesión del acusado para probar su culpabilidad, y los casos se decidían en audiencias orales a través de un juicio por jurados. Los jurados hacían una valoración libre de la prueba de acuerdo con sus impresiones sobre el caso y no había posibilidad de recurrir sus veredictos. Por el contrario, el sistema inquisitivo consistía en un proceso penal controlado por el tribunal, sometido a su propia iniciativa, y en el cual el tribunal tenía las funciones de investigar y juzgar el caso. El proceso inquisitivo procuraba obtener la confesión del imputado como parte de la investigación del caso, y llevaba a cabo los juicios mediante un procedimiento escrito y secreto realizado por jueces profesionales. Los jueces tenían que valorar la prueba de acuerdo con el sistema de prueba legal y existía la posibilidad de recurrir sus veredictos. ${ }^{8}$

Los doctrinarios de Europa continental concibieron los procesos acusatorio e inquisitivo como sistemas en los que había uno o varios principios epistemológicos, sociales o políticos subyacentes, que conectaban las características respectivas de cada uno de estos procesos. De ese modo, un número importante de doctrinarios consideró que cada sistema asumía una forma distinta de recolectar, producir y evaluar la prueba, y de determinar la verdad en los casos concretos. Así, de acuerdo con una de estas versiones, el sistema acusatorio asumía una concepción sintética de la investigación de la verdad porque cada una de las partes debía presentar las pruebas que sostenían sus afirmacio-

\footnotetext{
4 Respecto a la influencia del proceso penal inglés sobre los pensadores y otras figuras del Iluminismo, ver Padoa Schioppa (1986).

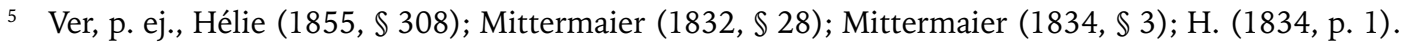

6 Ver, p. ej., Morgan (1930-1931, p. 906).

7 Ver, p. ej., Mittermaier (1832, $\mathbb{\$} 28)$.

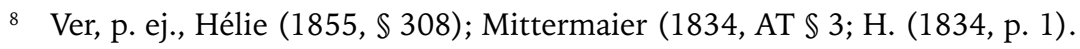


nes. Adicionalmente, asumía que la valoración correcta de la prueba solo requería del sentido común, educación y experiencia de cualquier ciudadano. Por su parte, el sistema inquisitivo tenía una concepción analítica de la determinación de la verdad porque cada paso procesal con sentido incriminatorio requería que hubiera indicaciones claras de que el acusado era culpable. Además, exigía que los jueces profesionales que eran designados por el gobierno utilizaran un sistema legal de valoración de la prueba, que se consideraba producto del conocimiento científico. ${ }^{9}$

Los autores europeo-continentales también consideraron que había una relación entre tipos de sociedad y tipos de proceso penal. Por ejemplo, en concordancia con las ideas del siglo XIX, algunos sostenían que el proceso acusatorio podía tener lugar en sociedades más primitivas o simples, tal como se desprendía de los juicios por ordalías y por juramento en la Edad Media, pero no en sociedades complejas o más avanzadas. ${ }^{10}$ Algunos doctrinarios asociaron al sistema acusatorio con una concepción democrática o popular del Estado que tenía como fin proteger los derechos y libertades individuales, y al sistema inquisitivo con una concepción autoritaria o monárquica del Estado que procuraba la aplicación eficiente del derecho penal. ${ }^{11}$ Parte de la doctrina defendió al sistema inquisitivo argumentando que se basaba en la razón y que castigaba el delito en forma solemne y equitativa. ${ }^{12}$ Con base en esta distinción entre sistemas acusatorios e inquisitivos, un grupo de doctrinarios caracterizó al Código de instrucción criminal de Napoleón, que prevaleció en Europa continental en el siglo XIX, como el "sistema mixto" que había encontrado el punto de equilibrio entre las libertades individuales y la eficiencia. ${ }^{13}$

\section{CONCEPCIONES TEÓRICAS CONTEMPORÁNEAS DE LAS CATEGORÍAS ACUSATORIO-INQUISITIVO}

La centralidad de la distinción acusatorio-inquisitivo para el derecho procesal penal comparado continúa hasta nuestros días. Sin embargo, aun cuando el significado asignado a estos términos en el siglo XIX haya establecido las bases para la configuración actual del derecho procesal penal comparado como disciplina teórica y como espacio de pensamiento y de reforma, lo cierto es que el derecho procesal penal comparado ha crecido y ha expandido sus bases teóricas en las últimas décadas. ${ }^{14}$ Desde una perspec-

\footnotetext{
9 Ver Mittermaier $(1834, \mathbb{S})$.

10 Ver, p. ej., Hélie (1855, $\$ 308)$; Mittermaier $(1809, \mathbb{\$} 1)$.

11 Ver, p. ej., Hélie (1855, $\mathbb{3} 308)$; Mittermaier $(1834, \mathbb{S} 3)$.

12 Ver, p. ej., Mittermaier $(1834, \mathbb{S} 3 ; 1809, \mathbb{S} 1)$.

13 Ver, p. ej., Hélie (1855, $\$ 308)$.

14 Para análisis generales sobre la disciplina del derecho procesal penal comparado, ver, por ejemplo, Grande (2012, p. 191 y ss.), Roberts (2002, p. 539 y ss. [reseña bibliográfica]).
} 
tiva teórica podemos distinguir al menos cinco usos contemporáneos de los términos adversarial o acusatorio, por un lado, e inquisitivo, por el otro. ${ }^{15}$ Aquellos que utilizan estas cinco concepciones teóricas no siempre las han articulado como tales, y a veces el mismo autor o actor ha utilizado los términos acusatorio e inquisitivo en más de uno de estos sentidos teóricos. Además, estos cinco usos no han sido igualmente importantes en los estudios teóricos y la invocación y aplicación práctica del derecho procesal penal comparado. Sin embargo, la articulación y el relevamiento de estas cinco concepciones son útiles, puesto que nos van a permitir identificar las principales tradiciones teóricas dentro del derecho procesal penal comparado en la actualidad.

Un primer uso teórico concibe a lo acusatorio y lo inquisitivo como tipos ideales descriptivos. No hay ningún proceso penal actual que contenga todas las características de uno de estos tipos ideales. Pero así como los edificios pueden acercarse en mayor o menor medida a un determinado estilo arquitectónico, los procesos penales pueden acercarse en mayor o menor medida a un determinado tipo ideal descriptivo sobre el proceso penal. ${ }^{16}$ Aquel que delinea los tipos ideales determina su contenido con base en una o más características que considera importante resaltar. Uno de los contenidos centrales, si no el más importante, que una parte de la doctrina ha incluido en los tipos ideales acusatorio-inquisitivo ha sido la contraposición entre el proceso penal como una contienda entre dos partes versus el proceso penal como una investigación imparcial única. ${ }^{17}$ No obstante, parte de la doctrina también ha incluido otras características en estos tipos ideales, como procedimiento oral versus escrito, proceso concentrado versus secuenciado y jueces legos versus profesionales, por mencionar algunas de ellas. ${ }^{18}$

Esta concepción ha sido fructífera a los fines clasificatorios, puesto que cualquier proceso penal puede ser ubicado en el espectro entre los tipos ideales acusatorio e inquisitivo. ${ }^{19}$ Además, como categorías weberianas, los tipos ideales pueden ser utilizados para describir características predominantes de las reglas o prácticas de un determinado proceso penal, permitiendo así el análisis comparado de temas específicos, como, por ejemplo, cuál proceso penal presenta más obstáculos probatorios para alcanzar una condena, ${ }^{20}$ o cuál protege mejor a los testigos vulnerables. ${ }^{21}$ La principal crítica a estos

15 Sobre las diferentes conceptualizaciones de las categorías acusatorio-inquisitivo, ver Langer (2001, p. 97 y ss.). En este artículo previo distinguí seis usos teóricos diferentes de las categorías "acusatorio" e "inquisitivo". Teniendo en cuenta que la definición de estas categorías como principios normativos complicaría innecesariamente el análisis en el presente trabajo me voy a concentrar aquí solo en los cinco usos restantes. Para un análisis más general de modelos procesales, ver, p. ej., Damaška (2001, p. 477 y ss.).

16 Ver, p. ej., Damaška (1984, p. 24 y ss.).

17 Ver, p. ej., Jackson (2005, p. 742-743).

18 Ver, p. ej., Jörg, Field y Brants (1995, p. 41 y ss.).

19 Ver, p. ej., Gane (1999), p. 56 y ss.).

20 Ver, p. ej., Damaška (1973, p. 506 y ss.).

${ }_{21}$ Ver, p. ej., Ellison (1999, p. 1 y ss.). 
tipos ideales ha sido que, incluso cuando pueden capturar los distintos tonos de grises entre dos opuestos procesales, no pueden explicar múltiples fenómenos procesales que no están incluidos en los tipos ideales. ${ }^{22}$ Por ejemplo, las formulaciones clásicas o predominantes sobre los tipos ideales acusatorio-inquisitivo no capturan los distintos grados de corrupción económica de los funcionarios del ministerio público y los jueces, los distintos niveles de recursos económicos y humanos con los que cuenta la administración de justicia penal, o los diferentes grados de capacidad investigativa de la policía en distintas jurisdicciones.

Un segundo sentido teórico concibe a lo acusatorio y a lo inquisitivo como sistemas históricos o sociológicos presentes en procesos penales concretos, pasados o contemporáneos, típicamente en las jurisdicciones anglosajonas y continental-europeas, o bien en un subgrupo dentro de ellas. Para una vertiente de esta concepción, el contenido de los sistemas acusatorio-inquisitivo se desprende del mínimo denominador común que las jurisdicciones continental-europeas y anglosajonas presentan en un momento determinado en el tiempo. ${ }^{23}$ Por ejemplo, si en un momento particular todas las jurisdicciones anglosajonas incluyen al jurado popular, mientras que todas las jurisdicciones continental-europeas incluyen a jueces profesionales como juzgadores del caso, entonces estas características pasan a ser parte, respectivamente, del contenido de los sistemas acusatorio e inquisitivo. El análisis mediante el mínimo denominador común ha sido criticado por su inestabilidad, ya que el contenido de las categorías se ve alterado con cada cambio que ocurre en cualquier jurisdicción continental-europea o anglosajona. ${ }^{24}$ Por ejemplo, si una sola jurisdicción continental-europea adopta el jurado, este rasgo ya no puede ser un elemento para distinguir entre los dos tipos de sistemas. Este análisis carece también de criterios sólidos para determinar el significado de los sistemas acusatorio-inquisitivo porque el contenido de las categorías depende de rasgos o modificaciones aleatorias en jurisdicciones individuales continental-europeas y anglosajonas, en vez de principios o fundamentos que subyacen y organizan a estas categorías.

Otras vertientes de esta segunda concepción teórica de los sistemas acusatorio-inquisitivo como categorías históricas o sociológicas no presentan estos problemas. Los investigadores definen las categorías con base en las características del proceso penal que quieren estudiar e investigan si existen principios o fundamentos que subyacen debajo de, y conectan estas características procesales entre sí. En esta vertiente incluyo una serie de estudios históricos sobre el proceso penal. En una importante versión de esta vertiente, la doctrina ha utilizado el término inquisitivo para referirse al proceso penal que nació en Europa continental entre los siglos XII y XIII, y prevaleció hasta comienzos del siglo XIX. Las características de este proceso han incluido el inicio del procedimiento penal por parte de los funcionarios públicos mediante iniciativa propia,

\footnotetext{
22 Markovits (1989, p. 1313 y ss. [reseña bibliográfica]).

23 Hermann (1978, p. 3).

24 Ver, p. ej., Damaška (1984).
} 
el sistema de pruebas legales, la limitación de los derechos del imputado y el uso de la tortura. ${ }^{25}$ La historiografía reciente ubica en el siglo XVIII los orígenes del sistema acusatorio, entendido como una contienda entre dos abogados frente a un juez y un jurado pasivos, regulada por las reglas contemporáneas del common law en materia probatoria, $y$ en donde el acusado tiene una serie de derechos en el juicio. ${ }^{26}$ En estos estudios históricos los procesos penales continentales contemporáneos a veces son caracterizados no como inquisitivos, sino como mixtos o no acusatorios. ${ }^{27}$ Estos análisis históricos han generado y aumentado nuestro conocimiento respecto no solo a la historia del proceso penal en distintas jurisdicciones, sino también al modo en que el proceso penal ha interactuado con diversos fenómenos, tales como la formación del Estado-nación, la expansión del poder de la Iglesia en la Edad Media y Moderna, y la profesionalización de la litigación penal entre los siglos XVIII y XIX, por mencionar solo algunos ejemplos. ${ }^{28}$

Otro uso de nuestros términos como sistemas históricos o sociológicos no se refiere a procesos penales del pasado sino a procesos penales contemporáneos de jurisdicciones continental-europeas y de otros lugares del mundo como América Latina, por un lado, y anglosajonas, por el otro lado, (o al menos de algunas de ellas dentro de cada uno de estos grupos). ${ }^{29}$ Así, por ejemplo, lo acusatorio se ha referido a un proceso penal concebido como una disputa entre dos partes ante un tribunal bifurcado, compuesto por un juez y un jurado, mientras que lo inquisitivo alude a un proceso penal concebido como una investigación imparcial única llevada a cabo por funcionarios públicos profesionales. Algunas investigaciones más recientes han caracterizado a estas dos concepciones del proceso penal (i) como un conjunto de normas culturales y sociales que estas instituciones y actores internalizan a través de procesos de socialización ${ }^{30}$ y (ii) como dos formas de distribuir el poder y las responsabilidades entre las principales instituciones y actores del sistema de justicia penal, tales como los fiscales, jueces, imputados, abogados defensores, víctimas y la ciudadanía. ${ }^{31} \mathrm{Y}$ en la medida en que los actores jurídicos usan los calificativos de acusatorio o common law e inquisitivo o continental-europeo para definirse a sí mismos como juristas, estas categorías también pueden ser entendidas como identidades legales, es decir, como términos para definirse a sí mismos como abogados vis-à-vis los abogados de otras jurisdicciones. ${ }^{32}$

25 Una referencia clásica en esta línea de trabajo es Esmein (1882). Para historiografía reciente relacionada con esta línea de investigación, ver, p. ej., Chiffoleau (2001), Kéry (2001).

26 Ver, p. ej., Langbein (2003).

27 Ver, p. ej., Langbein (2005).

28 Ver, p. ej., Chiffoleau (2001); Langbein (1978).

29 Ver, p. ej., Hodgson (2005).

30 Langer $(2004 ; 2005)$. Para una discusión crítica sobre el concepto de cultura jurídica con especial relación a la justicia penal, ver, p. ej., Nelken (1997; 2010).

31 Langer (2004).

32 Langer (2005). 
Esta conceptualización de los sistemas acusatorio e inquisitivo en términos de normas sociales y dinámicas de poder ha ayudado a entender cómo estos sistemas históricos o sociológicos se reproducen a sí mismos y cambian a lo largo del tiempo. ${ }^{33}$ También le ha permitido a parte de la doctrina y de los estudiosos del sistema penal analizar por qué las jurisdicciones continental-europeas y anglosajonas han regulado y discutido en forma distinta cuestiones jurídicas específicas como, por ejemplo, el derecho del imputado a acceder a los elementos de prueba en poder de las autoridades. ${ }^{34}$ Asimismo, ha contribuido a explicar cómo las reformas procesales de sistemas inquisitivos hacia acusatorios pueden ser rechazadas o transformadas por la jurisdicción receptora debido a diferentes normas culturales o a dinámicas de poder en los dos sistemas, y analizar por qué y cómo el proceso penal estadounidense se ha propagado hacia otras jurisdicciones. ${ }^{35}$ Dicha conceptualización también ha permitido explicar una serie de prácticas y resultados procesales en los tribunales penales internacionales en donde abogados educados y capacitados en sistemas locales con distintas normas procesales han perseguido, defendido y juzgado casos en forma conjunta. ${ }^{36}$

Estas dos primeras conceptualizaciones de lo acusatorio y lo inquisitivo como tipos ideales y como sistemas históricos o sociológicos también han permitido el análisis de lo que puede estar en juego en esta dicotomía desde una perspectiva epistemológica, sociológica o política. Una serie de estudios ha considerado que los modelos acusatorio e inquisitivo implican no solo dos técnicas distintas de determinación de los hechos y de adjudicación del caso, sino que también suponen concepciones diferentes de la verdad, en donde el modelo inquisitivo asume, por ejemplo, una teoría de la verdad como correspondencia, mientras que el modelo acusatorio asume una teoría consensual de la verdad. ${ }^{37}$ Esta línea epistemológica de investigación le ha permitido a la doctrina procesal penal comparada analizar no solo cuestiones teóricas sino también prácticas, como los posibles vínculos entre las condenas erróneas y los procesos acusatorio e inquisitivo. Por ejemplo, la doctrina ha puesto de manifiesto cómo los procesos acusatorios conducidos por las partes pueden tener problemas para identificar y cuestionar causas comunes que provocan condenas erróneas, tales como testigos oculares equivocados o mentirosos, confesiones y reconocimientos de culpabilidad falsos, prueba forense o pericial defectuosa y los prejuicios psicológicos de confirmación y de visión de túnel. ${ }^{38}$

\footnotetext{
33 Langer (2004).

34 Ver, p. ej., Langer y Roach (2013, p. 273).

35 Goldbach, Brake y Katzenstein (2013, p. 141 y ss.), Grande (2000), Langer (2004), Langer (2007, p. 617 y ss.), MacLeod (2010, p. 83), Pizzi (1993, p. 1325).

36 Langer (2005).

37 Ver, p. ej., Damaška (1997; 1990, p. 91 y ss.; 1998, p. 289 y ss.), Weigend (2011, p. 389 y ss.).

38 Ver, p. ej., Roach (2010, p. 387 y ss.). Para una crítica sobre la capacidad del sistema acusatorio norteamericano de alcanzar resultados veraces, ver Pizzi (1999). Sobre la relación entre los distintos tipos de prejuicios psicológicos y los procesos acusatorio e inquisitivo, ver, p. ej., Schünemann (1995, p. 215 y ss.), Van Koppen y Penrod (2003).
} 
Dentro de los círculos de la sociología jurídica, otros autores han vinculado al proceso acusatorio con concepciones individualistas de la sociedad y el puritanismo, y al proceso inquisitivo con concepciones comunitarias de la sociedad y el catolicismo. ${ }^{39}$ En teoría política, los procesos acusatorio e inquisitivo han sido relacionados con diferentes concepciones del Estado. En una de estas interpretaciones, el rol pasivo del tribunal en el proceso acusatorio ha sido vinculado con una concepción reactiva del Estado que permanece neutral frente a distintas concepciones del bien, mientras que el rol activo del tribunal en los procesos inquisitivos ha sido vinculado con un Estado que sostiene y promueve una determinada concepción del bien. ${ }^{40}$ En otra formulación, el proceso acusatorio ha sido relacionado con un Estado que implementa sus políticas a través del litigio legal, mientras que el proceso inquisitivo ha sido relacionado con un Estado que implementa sus políticas a través de una maquinaria burocrática. ${ }^{41}$ En otra enunciación el proceso acusatorio ha sido incluso vinculado con el Estado capitalista. ${ }^{42}$

Además de estas conceptualizaciones como tipos ideales o sistemas históricos o sociológicos, los términos acusatorio e inquisitivo han sido utilizados para referirse a intereses o valores opuestos dentro del proceso penal, en donde lo acusatorio se refiere al valor del debido proceso o los derechos del imputado, mientras que lo inquisitivo hace referencia al valor de la aplicación de la ley o la eficiencia. ${ }^{43}$ Esta tercera enunciación de las categorías acusatorio-inquisitivo no se concentra en las formas procesales utilizadas para la determinación de los hechos y la adjudicación del caso, sino en establecer qué características específicas de cada proceso penal promueven el debido proceso o la aplicación de la ley. En este sentido, lo acusatorio y lo inquisitivo son intereses o valores que podemos encontrar en distintos grados en todas las jurisdicciones, y no clasificaciones que corresponden respectivamente a las jurisdicciones anglosajonas y continental-europeas.

En un cuarto sentido teórico, lo acusatorio y lo inquisitivo son utilizados para describir una o más funciones que los procesos penales llevan a cabo. En esta cuarta conceptualización, aquellos procesos penales que están estructurados para obtener admisiones de culpabilidad en forma sistemática o coaccionada han sido caracterizados como inquisitivos, en tanto que aquellos otros que no están estructurados para obtener estas admisiones de culpabilidad serían acusatorios. ${ }^{44}$ Esta conceptualización no se ha concentrado en las formas procesales sino en las funciones reales que desempeña el proceso penal. Esta cuarta concepción de las categorías acusatorio-inquisitivo puede vincularse con la tradicional escuela funcionalista del derecho comparado, que en lugar de buscar las

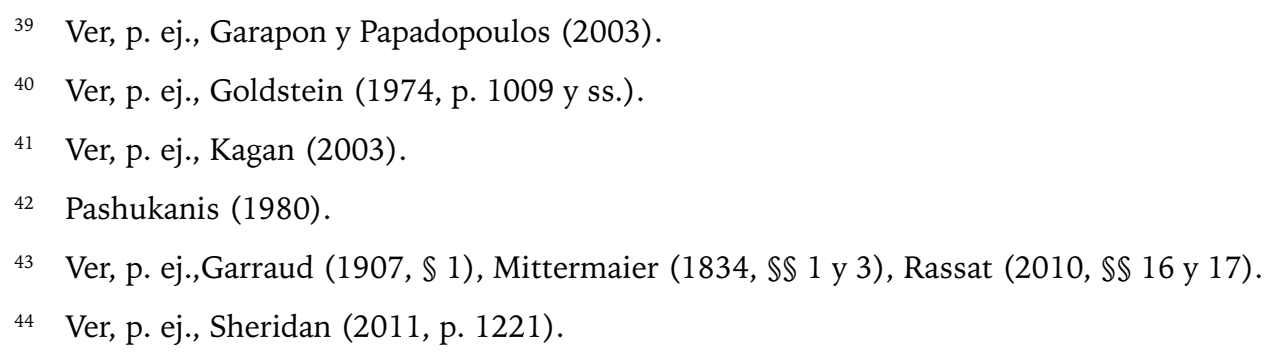


diferencias de forma entre los sistemas jurídicos analiza si estos cumplen funciones similares utilizando diferentes formas. ${ }^{45}$

Esta cuarta conceptualización teórica tiene un antiguo pedigrí en el derecho procesal penal comparado debido a la asociación entre el término inquisitivo y la práctica de la tortura en el Antiguo Régimen. ${ }^{46}$ La asociación entre las confesiones obtenidas en forma coaccionada y el derecho continental-europeo todavía persiste hasta nuestros días, especialmente en el mundo anglosajón. ${ }^{47}$ No obstante, en contra de estas caracterizaciones simplistas, algunos especialistas en derecho procesal penal comparado han sostenido que algunos de los orígenes del derecho contra la autoincriminación compulsiva pueden encontrarse en el derecho continental-europeo, y que actualmente las jurisdicciones continental-europeas reconocen ese derecho. ${ }^{48}$ Además, invirtiendo el clásico argumento funcionalista del derecho procesal penal comparado, algunos estudios han mostrado que, a pesar de los estereotipos preexistentes, algunas jurisdicciones anglosajonas contemporáneas dependen de la obtención sistemática o coercitiva de admisiones de culpabilidad tanto como o de modo más problemático que varias jurisdicciones continental-europeas y latinoamericanas. En estas jurisdicciones anglosajonas, estas admisiones de culpabilidad son gestionadas u obtenidas por los fiscales y ocurren como declaraciones de culpabilidad del acusado luego de la emisión de la acusación, en lugar de ser confesiones ante la policía o el juez de instrucción. ${ }^{49}$ La asociación entre las jurisdicciones anglosajonas y el derecho contra la autoincriminación compulsiva se ha visto debilitada aun más por la autorización en Inglaterra y Gales a los jurados para realizar inferencias negativas en determinadas situaciones con base en el silencio del imputado, así como por la autorización en los Estados Unidos para utilizar técnicas como el ahogamiento simulado (submarino) durante el gobierno de Bush como parte de sus políticas antiterroristas. ${ }^{50}$

En una quinta conceptualización teórica, lo acusatorio y lo inquisitivo son utilizados como modelos normativos. Estos modelos incluyen un conjunto de principios o características positivas o negativas que pueden usarse para evaluar procesos penales actuales, para tomar decisiones en casos individuales o para promover reformas procesales. Los argumentos a favor de la superioridad normativa de los procesos acusatorio o inquisiti-

45 Ver, p. ej., Zweigert y Kötz 1998).

46 Para descripciones y análisis históricos sobre la tortura en el proceso penal del Antiguo Régimen, ver, $\mathrm{p}$. ej., Damaška (1978; 2012), Langbein (1976), Pennington (1993).

47 Ver, p. ej., Colorado v. Connelly, (1986) 479 U.S. 157, 181; Rogers v. Richmond, (1961) 365 U.S. 534, 81 S.Ct. 735, 5 L.Ed.2d 760.

48 Ver, p. ej., Helmolz et al. (1997), Van Kessel (1998).

49 Langbein (1978, p. 3 y ss.), Langer (2006). Para un análisis comparado sobre los fiscales como adjudicadores de hecho, ver, p. ej., Luna y Wade (2012).

50 Sobre la regulación del derecho contra la autoincriminación forzada en Inglaterra y Gales, ver, p. ej., Feldman (2007, p. 149). 
vo se han basado en la supuesta superioridad epistemológica, en la mayor consistencia con los derechos humanos, en la mayor transparencia, en el carácter democrático o en la mayor eficiencia del proceso acusatorio sobre el inquisitivo, o viceversa. ${ }^{51}$ Al igual que en las conceptualizaciones previas, los doctrinarios y otros actores les han asignado diferente contenido a los procesos acusatorio e inquisitivo como modelos normativos de acuerdo con las cuestiones que les interesa analizar o promover. ${ }^{52}$ Este contenido ha incluido temas clásicos para estas categorías, tales como la oposición entre proceso conducido por las partes versus proceso conducido por el tribunal, audiencias orales versus expediente escrito, procesos públicos versus secretos, reconocimiento pleno versus reconocimiento débil de los derechos del imputado y jurados puros versus tribunales mixtos o jueces profesionales. Frecuentemente, estos argumentos normativos han sido articulados junto con propuestas de reformas, parciales o totales, sean acusatorias en o para jurisdicciones continental-europeas o latinoamericanas, o bien reformas inquisitivas en o para jurisdicciones anglosajonas. ${ }^{53}$

También los tribunales han realizado un uso normativo de estas categorías. En este sentido, el Tribunal Europeo de Derechos Humanos ha sostenido que la Convención Europea sobre Derechos Humanos exige un proceso acusatorio que incluye el derecho a la igualdad de armas, entendido como el derecho de cada parte a que se le otorgue una oportunidad razonable para presentar su caso en condiciones tales que no lo ubiquen en una desventaja sustancial frente a su oponente. ${ }^{54} \mathrm{El}$ derecho a un proceso acusatorio significa, en un caso penal, que tanto el acusador como la defensa deben tener la oportunidad de tener conocimiento y pronunciarse sobre las observaciones presentadas y la prueba invocada por la otra parte. ${ }^{55}$ Este derecho incluye que el acusado tenga una oportunidad adecuada y apropiada para impugnar y cuestionar a los testigos contra él, sea al momento en que prestan declaración o bien en una etapa posterior del procedimiento. ${ }^{56}$ A fin de acomodar tanto a las jurisdicciones anglosajonas como a las continental-euro-

51 Para un análisis crítico de las justificaciones consecuencialistas y no consecuencialistas del sistema acusatorio, ver Luban (1988, p. 67-102). Sobre el presunto superior o inferior valor epistemológico del sistema acusatorio, ver, p. ej., Ferrajoli (2009), Menkel-Meadow (1996). Sobre la presunta mayor consistencia del sistema acusatorio o inquisitivo con los derechos humanos, con la transparencia y, de manera más general, con la democracia, ver, p. ej., Binder (1993), Maier (1996) y Schünemann (2008). Sobre si los sistemas acusatorio o inquisitivo son más eficientes, ver, p. ej., Posner (1999).

52 Algunos autores consideran que un proceso penal legítimo tiene que combinar aspectos de las categorías acusatorio e inquisitivo más que optar por uno sobre el otro. Ver, p. ej., Vogler (2005) quien sostiene que los procesos penales legítimos deben combinar elementos de las tradiciones acusatoria, inquisitiva y de justicia popular.

53 Ver, p. ej., Binder (1993), Weinreb (1977), Amodio y Selvaggi (1989), Frase (1990), Frase y Weigend (1995), Iontcheva Turner (2006), Langbein (1981).

54 Ver, p. ej., Kennedy v. United Kingdom (26839/05), (2011) 52 E.H.R.R. 4, $\mathbb{1} 184$.

55 Ver, p. ej., Fitt v. United Kingdom (29777/96), (2000) 30 E.H.R.R. 480, $\mathbb{S} 44$; Rowe and Davis v. the United Kingdom [GC], no. 28901/95, ECHR 2000-II, $\$ 60$.

56 Ver, p. ej., Kostovski v. The Netherlands (11454/85), (1989) 12 E.H.R.R. 434, $\$ 41$. 
peas, el Tribunal Europeo no ha incluido en el contenido del proceso acusatorio muchas características que se encuentran en el common law. De esta forma, el Tribunal ha exigido que tanto las jurisdicciones anglosajonas como las continental-europeas modifiquen sus procedimientos, dejándoles al mismo tiempo suficiente lugar para que mantengan muchas de sus normas e instituciones preexistentes. ${ }^{57}$

Pero aun cuando se han dado argumentos normativos a favor del sistema inquisitivo, el sistema acusatorio ha tendido a imponerse en este debate normativo, especialmente en los últimos años. Esta preferencia por el proceso acusatorio puede ser, parcialmente, resultado de la discusión teórica y de razones sustantivas. Sin embargo, hay otros fenómenos que pueden ayudar a explicar por qué el proceso acusatorio es considerado el modelo procesal más atrayente: uno, la influencia que ejerce el proceso penal de los Estados Unidos y sus agencias alrededor del mundo, y, dos, la vieja asociación entre el término inquisitivo y el proceso penal del Antiguo Régimen. Esta connotación positiva y negativa, respectivamente, de lo acusatorio y lo inquisitivo contribuye a explicar por qué los términos han sido utilizados como dispositivos retóricos y eslóganes en fallos penales y para fundamentar reformas procesales penales alrededor del mundo. ${ }^{58}$

\section{ANÁLISIS COMPARADOS ALTERNATIVOS DEL PROCESO PENAL Y LA LARGA SOMBRA TEÓRICA DE LO ACUSATORIO-INQUISITIVO}

Dada la importancia de las categorías acusatorio-inquisitivo para el derecho procesal penal comparado, no es sorprendente que la doctrina haya articulado diversos marcos teóricos alternativos a ellas. En esta sección sostengo que aun cuando estos análisis alternativos con frecuencia han profundizado nuestro conocimiento y nuestra comprensión del proceso penal, estos análisis pueden ser considerados meras elaboraciones de las categorías acusatorio-inquisitivo, o como todavía operando bajo su larga sombra teórica. Mi análisis de estos abordajes alternativos va a seguir en forma secuencial el relevamiento teórico de la oposición acusatorio-inquisitivo de la sección anterior como: (1) tipos ideales descriptivos; (2) sistemas históricos o sociológicos presentes en procesos penales concretos pasados o contemporâneos; (3) intereses o valores contrapuestos que coexisten en todo proceso penal; (4) funciones del proceso penal; y (5) modelos normativos.

El más influyente y sofisticado de estos análisis alternativos ha sido el marco teórico elaborado por Mirjan Damaška en su obra Las caras de la justicia y la autoridad estatal. ${ }^{59}$ Damaška propone dos grupos de tipos ideales opuestos en lugar de las clásicas catego-

\footnotetext{
57 Ver, p. ej., Jackson (2005).

58 Ver, p. ej., Amodio y Selvaggi (1989), Langer (2007), Sklansky (2009).

59 Damaška (1986).
} 
rías acusatorio-inquisitivo a fin de evitar "construcciones estrechas y estériles" y "vanos intentos para expresar el núcleo de oposición entre la administración de justicia continental y angloamericana". ${ }^{60}$ Un primer grupo de tipos ideales opuestos incluye los ideales de la jerarquía y de la coordinación que articulan dos formas mediante las cuales se estructura la autoridad en la administración de justicia. En el modelo ideal de la jerarquía, la administración de justicia está compuesta por profesionales que toman decisiones aplicando reglas técnicas a los casos, en unmarco de relaciones jerárquicas de autoridad entre ellos. En contraste, en el modelo ideal de la coordinación, la administración de justicia está compuesta por legos que toman decisiones sobre los casos aplicando estándares comunitarios, en un esquema de relaciones horizontales de autoridad entre ellos. El segundo grupo de tipos ideales opuestos de Damaška incluye los modelos de implementación de políticas públicas y de resolución de conflictos que articulan dos objetivos que la administración de justicia puede perseguir. En el modelo de resolución de conflictos, el objetivo de la administración de justicia y del Estado es brindar un marco dentro del cual los individuos puedan elegir entre sus propias concepciones del bien. En contraste, en el modelo de implementación de políticas públicas, el fin de la administración de justicia y el Estado es implementar una determinada concepción del bien.

Esta iluminadora construcción de Damaška vino a renovar el estudio comparado de los procesos legales al proveer dos grupos originales de tipos ideales que conectan características del proceso legal con dos tipos de autoridad y dos objetivos de la administración de justicia. ${ }^{61}$ Sin embargo, a pesar de su originalidad e importancia, este esquema puede ser considerado como una elaboración de las categorías acusatorio-inquisitivo más que como una verdadera alternativa a estas. En primer lugar, al igual que una importante vertiente de la literatura sobre lo acusatorio-inquisitivo, la propuesta de Damaška reposa en tipos ideales como dispositivos teóricos. En otras palabras, al igual que aquella corriente sobre lo acusatorio-inquisitivo, Damaška crea modelos abstractos como una forma de clasificar y analizar los procesos legales actuales. Además, sus modelos de resolución de conflictos y de implementación de políticas públicas pueden ser considerados como elaboraciones de la clásica oposición acusatorio-inquisitivo entre proceso de partes versus investigación única, mientras que los modelos de la coordinación y de la jerarquía pueden ser entendidos como elaboraciones de la clásica oposición acusatorio-inquisitivo entre juzgadores legos versus juzgadores profesionales. Los modelos de resolución de conflictos y de implementación de políticas públicas también pueden ser interpretados como una elaboración del clásico tema del derecho procesal penal comparado sobre el vínculo que existe entre tipos de procesos penales y tipos de Estado político. Así como en las articulaciones clásicas lo acusatorio está vinculado a una concepción democrática y lo inquisitivo a una concepción autoritaria o monárquica del Estado, el esquema de Damaška relaciona al proceso estructurado como una disputa

60 Damaška (1986, p. 6).

61 Sobre la importancia e influencia del trabajo de Damaška, ver Jackson, Langer y Tillers (2008). 
con una concepción liberal del Estado y al proceso estructurado como una investigación única con una concepciónno liberal del Estado. La contribución de Damaška ha sido importante y novedosa pero opera dentro del espacio intelectual o de pensamiento que la literatura sobre los sistemas acusatorio e inquisitivo ya había abierto.

Un segundo grupo de abordajes alternativos ha incluido análisis históricos y sociojurídicos del proceso penal que no reposan (principalmente) en la distinción acusatorio-inquisitivo, y en su lugar proponen otros conceptos para comparar las jurisdicciones anglosajonas y continental-europeas. Estos estudios también han profundizado nuestro entendimiento del proceso penal al sostener, por ejemplo, que distintas concepciones de participación ciudadana en la decisión de los casos pueden reflejar diferentes concepciones de qué es una "nación"; que las relaciones entre las agencias de justicia penal y las instituciones locales no estatales son descritas en forma disímil en diferentes países debido a distintas actitudes hacia la idea de "comunidad"; que distintas preocupaciones sobre la vigilancia encubierta reflejan diferentes nociones sobre sus objetivos y los problemas que presenta; que existe un vínculo entre la discrecionalidad en la persecución penal y distintas concepciones sobre la igualdad; que diferencias en las regulaciones legales pueden ser una manifestación de distintas concepciones de la privacidad; y que las grandes diferencias en la forma en que se trata la prueba sobre la personalidad del acusado reflejan diferentes concepciones sobre las relaciones entre el Estado y la ciudadanía en las jurisdicciones anglosajonas y continental-europeas, o en un subgrupo de ellas; por mencionar solo algunos ejemplos. ${ }^{62}$

No obstante ello, una vez más, se puede considerar que estos estudios operan dentro de un ámbito de pensamiento teórico ya abierto por la literatura sobre los procesos acusatorio-inquisitivo. Al igual que las caracterizaciones de lo acusatorio y lo inquisitivo como sistemas históricos o sociológicos, estos análisis toman a las jurisdicciones anglosajonas y continental-europeas (o un subgrupo de ellas) como una división central dada, que puede ser explicada mediante la identificación de principios o fundamentos que subyacen a cada una de estas clases de jurisdicción. Además, el tipo de explicaciones propuestas actúa dentro de la tradición culturalista del derecho procesal penal comparado que considera que los distintos valores, normas sociales o concepciones políticas constituyen las variables independientes que explican las diferencias jurídicas entre los procesos penales de las jurisdicciones anglosajonas y continental-europeas.

Un tercer conjunto de explicaciones alternativas a la oposición acusatorio-inquisitivo ha aplicado los modelos clásicos de Herbert Packer sobre el control del delito y el debido proceso al análisis comparado del proceso penal. Mientras que bajo el modelo del control del delito el proceso penal es una línea de montaje que tiene como principal objetivo la aplicación eficiente del derecho penal a través del plea bargaining, bajo el modelo del debido proceso el procedimiento penal constituye una carrera de obstáculos que resaltan la protección de los derechos del imputado a través de un juicio ante un

62 Ver, p. ej., Dubber (1995), Field (2006), Lacey y Zedner (1998), Ross (2007), Whitman (2009; 2004). 
tribunal imparcial. ${ }^{63}$ Si bien Packer consideraba a los modelos del control del delito y del debido proceso como un reflejo de la tensión entre dos sistemas de valores dentro del proceso acusatorio de los Estados Unidos, ${ }^{64}$ parte de la doctrina los ha utilizado para el análisis comparado del proceso penal. ${ }^{65}$

Es difícil exagerar la influencia de los modelos de Packer sobre las reflexiones sobre proceso penal no solo en los Estados Unidos sino también en otros lugares del mundo. ${ }^{66}$ Packer articuló elegantemente sus dos detallados modelos para captar una tensión clásica dentro del proceso penal. Sin embargo, él no fue el primero en advertir esta tensión. De hecho, como ya mencioné, mucho antes que Packer un número de especialistas en derecho procesal penal comparado habían considerado que esta misma tensión entre la aplicación eficiente del derecho penal y el debido proceso era captada por la oposición entre el proceso penal acusatorio e inquisitivo - y probablemente tampoco ellos fueron los primeros en identificar y articular dicha tensión. Lo que quiero señalar es que los modelos de Packer pueden ser considerados no como verdaderas alternativas a una de las tradiciones teóricas operando mediante las categorías acusatorio-inquisitivo, sino como elaboraciones dentro de una corriente de pensamiento sobre el proceso penal que ya había sido abierta y que ya estaba presente en la literatura sobre el proceso penal comparado.

Una cuarta serie de análisis alternativos se ha concentrado en las funciones que desempeña el proceso judicial más que en las formas que presenta. Probablemente el análisis comparado de Martin Shapiro ha sido el más sofisticado en esta conceptualización. Shapiro cuestiona el entendimiento predominante sobre los tribunales, que incluye: “(1) un juez independiente que aplica (2) normas legales preexistentes (3) después de un procedimiento acusatorio (4) a fin de alcanzar una decisión dicotómica en la cual a una de las partes se le asigna un derecho y a la otra se la considera equivocada". ${ }^{67}$ En lugar de ello, explora el rol que juega el consentimiento para legitimar a los órganos juzgadores y destaca las funciones de resolución de conflictos, creación del derecho y control social que estos órganos llevan a cabo. ${ }^{68}$

La obra de Shapiro ha hecho una importante contribución al análisis comparado del proceso judicial. Al poner el énfasis en la necesidad de obtener consentimiento y en las funciones que realizan los órganos juzgadores, Shapiro cuestiona la concepción predominante sobre los tribunales y brinda una perspectiva fresca al estudiarlos como parte del espectro de órganos que cumplen funciones de resolución de conflictos, creación del

\footnotetext{
63 Packer (1964).

64 Packer (1964, p. 7-9).

65 Ver, p. ej., Luna (2004), Roach,(1999).

66 Para un análisis crítico de los modelos de Packer ver, p. ej., Griffiths (1970). Para un estudio reciente sobre el trabajo de Packer y las principales reacciones que generó, ver Aviram (2011).

67 Shapiro (1981, p. 1).

68 Shapiro $(1981$, p. 1).
} 
derecho y control social en cualquier tipo de sociedad. Sin embargo, esta perspectiva teórica opera dentro de la escuela funcionalista del derecho comparado que ha sido aplicada a las categorías acusatorio-inquisitivo en particular, y al proceso penal y al derecho comparado en forma más general desde, al menos, la primera mitad del siglo XX ${ }^{69} \mathrm{Al}$ igual que esta vertiente funcionalista, Shapiro cuestiona la importancia del discurso legal y las formas procesales, y en su lugar se concentra en las funciones que realizan los tribunales y los procesos. Sus contribuciones son nuevas pero operan dentro de un espacio teórico que ya estaba presente en los estudios comparados.

Un quinto grupo de análisis alternativos se ha basado en una perspectiva normativa sobre el proceso penal. Estos abordajes han cuestionado la distinción acusatorio-inquisitivo y han intentado ir más allá al proponer reformas procesales o interpretaciones de textos legales procesales con base en instrumentos de derechos humanos regionales o universales, o en ciertas tradiciones procesales. ${ }^{70}$ Estas reformas e interpretaciones han incluido, por ejemplo, propuestas de que los tribunales penales no tengan funciones investigativas o que solo la prueba producida en el juicio pueda servir como base para una condena. De acuerdo con estas posturas, uno de los problemas con las categorías acusatorio-inquisitivo es que remiten, respectivamente, a las jurisdicciones anglosajonas y continental-europeas. Por lo tanto, estos abordajes han considerado que las propuestas de reforma inspiradas en los modelos acusatorio e inquisitivo pueden dar lugar a reacciones nacionalistas que pueden obstaculizar las discusiones de fondo y los esfuerzos de reforma. ${ }^{71}$

Estas propuestas normativas han enriquecido la discusión a nivel nacional, regional y global sobre el modo en que debe ser estructurado el proceso penal. Por ejemplo, el trabajo de la Comisión Delmas-Marty en Francia dio lugar a un debate sobre si la figura del juez de instrucción es compatible con los estándares internacionales o europeos de debido proceso. Sin embargo, al estudiar estos modelos alternativos en detalle vemos que presentan similitudes y paralelos sustanciales con las concepciones normativas de los sistemas acusatorio e inquisitivo descritas anteriormente. De hecho, los elementos de estos modelos normativos incluyen muchos de los elementos de los modelos normativos acusatorios, tales como la distinción tajante entre las funciones de acusar y juzgar, la eliminación del juez de instrucción en la etapa preliminar, la concepción del proceso penal en términos de una "trinidad acusatoria", el fortalecimiento de los derechos del acusado, la introducción de mecanismos de acuerdo entre la acusación y la defensa, y el fortalecimiento de los juicios orales y públicos. ${ }^{72}$

69 Sobre la escuela funcionalista del derecho comparado, ver, p. ej., Zweigert y Kötz (1998).

70 Ver, p. ej., La mise en état des affaires pénales. Commission justice pénale et droits de l'homme (1991), Summers (2007).

71 Ver., p. ej., Summers (2007, p. 11-13).

72 Ver, p. ej., La mise en état (nota 69), Summers (2007). 


\section{LA SOMBRA TEMÁTICA DE LAS CATEGORÍAS ACUSATORIO-INQUISITIVO}

En este apartado sostendré que la sombra de las categorías acusatorio-inquisitivo es aún más larga que lo señalado anteriormente. Y esto es así porque lo acusatorio y lo inquisitivo comparten con los análisis alternativos del derecho procesal penal comparado no solo las tradiciones teóricas, sino también un interés limitado a solamente ciertos aspectos del proceso penal. Mi principal argumento es que la yuxtaposición de las categorías acusatorio e inquisitivo ha resaltado a determinadas jurisdicciones y a ciertos aspectos de la administración de justicia en detrimento de otros. Por limitaciones de espacio, aquí solo puedo esbozar, más que demostrar, mis afirmaciones sobre esta cuestión.

En primer lugar, el derecho procesal penal comparado se ha interesado mayormente en entender y explicar las diferencias entre las jurisdicciones anglosajonas y continental-europeas. Este interés no ha sido exclusivo pero ha estado en el centro de la disciplina por mucho tiempo. ${ }^{73} \mathrm{La}$ importancia de las categorías acusatorio-inquisitivo y su asociación con las jurisdicciones anglosajonas y continental-europeas respectivamente, probablemente ha contribuido a perpetuar las limitaciones geográficas de este campo de pensamiento. Esta asociación le ha dado un rol central a Inglaterra, Estados Unidos, Francia, Alemania e Italia como las principales jurisdicciones que deben ser explicadas debido a que los sistemas acusatorios e inquisitivos han sido abstracciones de los procesos penales de estos países, o bien porque estas jurisdicciones son consideradas las más influyentes en el mundo o en donde se originaron los sistemas acusatorio e inquisitivo. Estas limitaciones han marginalizado a los procesos penales de países de menores recursos y países no occidentales, lo cual ha contribuido a que el derecho procesal penal comparado sea mayormente una empresa destinada a entender las diferencias dentro de los países desarrollados de Occidente, en lugar de un verdadero ejercicio global.

En segundo término, si bien el derecho procesal penal comparado ha considerado que las jurisdicciones individuales pueden ser miembros de familias jurídicas y que estas jurisdicciones individuales pueden influirse entre sí, el derecho procesal penal comparado ha puesto su interés, casi en forma exclusiva, en un proceso penal que investiga y persigue casos dentro de una única jurisdicción, generalmente dentro de un mismo Estado-nación. La persecución de casos cuyos delitos, personas o elementos probatorios se encuentran fuera de los límites de la competencia del Estado que ejerce la persecución penal ha generado interés en las disciplinas y campos de pensamiento y de reforma del derecho penal transnacional, las relaciones internacionales y el derecho internacional, pero muy poco por parte de los comparativistas del procesal penal. Esta falta de interés puede estar relacionada con el hecho de que el derecho procesal penal

73 Han existido algunas excepciones a esta tendencia. Un ejemplo reciente son Paul Roberts y Jill Hunter (2012) (explorando el impacto de los derechos humanos en una amplia gama de jurisdicciones del common law). 
comparado fue moldeado como una disciplina con lo acusatorio-inquisitivo como categorías centrales antes de que el delito transnacional se convirtiera en un fenómeno global importante. Dentro del paradigma tradicional del derecho procesal penal comparado, el objetivo ha sido explicar las diferencias en el modo en que las jurisdicciones anglosajonas y continental-europeas persiguen y juzgan sus propios delitos locales, más que en el modo en que las jurisdicciones pueden interactuar entre ellas en la persecución y juzgamiento de sus casos individuales. ${ }^{74}$

Tercero, el derecho procesal penal comparado se ha centrado en perspectivas de derecho positivo, institucionales y de rol. Este espacio de pensamiento se ha interesado en su mayor parte en explicar por qué las jurisdicciones anglosajonas y continental-europeas presentan distintas normas e instituciones para perseguir y juzgar el delito, y por qué a los fiscales, jueces, abogados defensores y otros actores se les asigna roles distintos en cada clase de jurisdicción. También se ha dedicado a explicar cuáles pueden ser los principios o fundamentos que subyacen a cada una de estas diferentes regulaciones de derecho positivo, institucionales y de rol, y en evaluar cuáles son las más atractivas. ${ }^{75}$ Sin embargo, ha explorado muy poco otras cuestiones, como, por ejemplo, en qué medida y por qué los procesos penales en diferentes jurisdicciones tienen los mismos o diferentes clases de "clientes" (ej. víctimas, acusados, testigos, peritos etc.). Una vez más, esto puede ser el resultado de que la comparación entre sistemas acusatorios e inquisitivos pone de relieve determinadas diferencias de derecho positivo, institucionales y de rol, en detrimento de muchas otras posibles diferencias y puntos en común que presentan las prácticas de la justicia penal en distintas jurisdicciones.

En cuarto lugar, a pesar de su perspectiva institucional y de rol, la doctrina y los estudios comparados sobre el proceso penal han mostrado interés básicamente en un limitado conjunto de instituciones y actores de la justicia penal —aquellos relacionados con el proceso formal de persecución y juzgamiento-. Nuevamente, esto puede ser el resultado de que la comparación de los procesos acusatorio e inquisitivo resalta las diferencias entre determinadas instituciones y actores, como la fiscalía, los tribunales y los abogados, en lugar de otras como la policía, las oficinas que controlan a los sometidos a suspensión del juicio a prueba y los procedimientos posteriores a la condena y a los recursos, por mencionar solo algunas posibilidades.

Por ejemplo, el derecho procesal penal comparado ha hecho muy poco para explicar a la policía como institución. Sin lugar a dudas, las facultades y regulaciones legales de la policía suelen ser tratadas por los análisis comparados del proceso penal. ${ }^{76}$ Pero es muy poco lo que sabemos sobre el diferente modo de operar de las fuerzas policiales en

\footnotetext{
74 Para una excepción a esta afirmación en donde se hace un análisis comparado de este tipo de cuestiones, ver, Keitner (2011).

75 Un ejemplo de buena calidad de este tipo de descripción y análisis de derecho positivo, institucional y de rol: Delmas-Marty y Spencer (2002).

76 Ver, p. ej., Bradley (2007), Thaman (2008).
} 
el proceso penal en relación con los distintos grupos sociales, cómo están demográficamente compuestos los departamentos policiales e incluso cómo están estructurados como organización en distintas jurisdicciones. ${ }^{77}$ Este limitado interés y análisis sobre la policía puede ser una consecuencia de que en todo el mundo esta es, por definición, inquisitiva, en el sentido de que investiga casos por iniciativa propia. Por lo tanto, es posible que la oposición acusatorio-inquisitivo no sea la más adecuada para despertar el interés y estudio sobre todas las distintas configuraciones que estas instituciones inquisitivas pueden tener.

\section{TRASCENDIENDO LA LARGA SOMBRA DE LAS CATEGORÍAS ACUSATORIO-INQUISITIVO}

En este trabajo he identificado las principales tradiciones teóricas del derecho procesal penal comparado, así como los principales temas en los que se ha interesado. Pero estas limitaciones teóricas y temáticas no son exclusivas de este campo del pensamiento, del saber y de las políticas públicas. Toda disciplina utiliza un conjunto limitado de tradiciones teóricas y tiene su propio grupo de temas centrales. De hecho, en comparación con otras disciplinas y espacios de pensamiento, el derecho procesal penal comparado ha trabajado con un amplio espectro de escuelas teóricas que le han permitido producir valiosos conocimientos y perspectivas para comprender y analizar el proceso penal.

Sin embargo, si el derecho procesal penal comparado pretende ampliar y profundizar su conocimiento y análisis del proceso penal, debe entonces trascender las categorías acusatorio-inquisitivo y su larga sombra. La idea de este trabajo es que la identificación de estos temas y tradiciones teóricas contribuya a que la doctrina y otros analistas, los actores e instituciones de la justicia penal y los responsables de las políticas públicas en esta materia logren trascender al menos algunas de estas limitaciones, de manera tal que el derecho procesal penal comparado sea un ámbito de investigación, análisis y reforma aun más sólido y fructífero.

Existen muchos caminos mediante los cuales se puede superar la sombra de estas categorías. Aquí solo voy a delinear algunos posibles. Como punto de partida es importante distinguir entre los niveles positivo y normativo. Si bien hay suficiente espacio para ambos tipos de análisis bajo el gran paraguas del derecho procesal penal comparado, los niveles positivo y normativo presentan diferentes tipos de cuestiones, métodos y desafíos que deben ser abordados por separado. De hecho, uno de los problemas con algunos de los modos en que se han usado las categorías acusatorio-inquisitivo es que con frecuencia se han confundido estos dos niveles.

77 Una notable excepción es el trabajo de David. H Bayley al cual la doctrina del derecho procesal penal comparado le ha prestado poca atención. Ver su obra: Patterns of policing (1990) y changing the guard. Developing democratic police abroad (2006). Ver también Ambos, Gómez y Vogler (2003). 
En el plano positivo hay al menos tres cuestiones para tener en cuenta. Primera, como ya expliqué, una vertiente muy importante del derecho procesal penal comparado se ha basado fuertemente en modelos para analizar el proceso penal. No hay dudas de que estas herramientas le han permitido al derecho procesal penal comparado articular diferentes concepciones del proceso penal, analizar las normas culturales predominantes así como también las dinámicas institucionales en jurisdicciones específicas, identificar diferentes marcos epistemológicos sobre la verdad en el proceso penal, y explorar el tipo de relación entre estas concepciones procesales y los distintos tipos de sociedades, marcos epistemológicos y sistemas políticos.

No obstante, estos modelos son menos capaces de producir otro tipo de conocimiento positivo porque son modelos multidimensionales. En otras palabras, los sistemas o tipos ideales del derecho procesal penal comparado aluden a múltiples características del proceso penal a la vez, tal como ocurre con la inclusión en estos modelos o sistemas opuestos de rasgos tales como la discrecionalidad versus la obligatoriedad en la persecución penal, las declaraciones de culpabilidad que pueden terminar con la fase de juzgamiento (guilty pleas) versus la ausencia de esta clase de declaraciones, el tribunal como un árbitro pasivo o como un investigador activo, la recolección de pruebas en manos de las partes versus en manos de un órgano imparcial, los jurados legos versus los jueces profesionales, las audiencias orales versus el expediente escrito, los procedimientos públicos versus secretos, el proceso penal concentrado versus el proceso penal secuencial, entre otros.

Además, aun cuando estos múltiples rasgos del proceso penal son reducidos a unas pocas variables subyacentes, estas variables por lo general siguen siendo múltiples. Por ejemplo, lo acusatorio y lo inquisitivo suelen ser definidos usando dos grupos de variables opuestas, tales como disputa entre partes versus investigación imparcial única y proceso concentrado versus proceso secuencial. E incluso cuando estas variables subyacentes son claramente separadas entre sí como variables independientes, cada una de ellas suele ser de por sí multidimensional. En este sentido, para tomar un ejemplo sofisticado, esto es lo que ocurre con los modelos de la coordinación y de la jerarquía de Damaška que incluyen cada uno de ellos no una sino tres variables: decisores legos versus decisores profesionales, relaciones horizontales versus relaciones verticales entre los que deciden y estándares comunitarios versus reglas técnicas de adjudicación.

No es que pretenda descartar los modelos multidimensionales. El derecho procesal penal comparado ha podido producir mucho conocimiento positivo sustancial a través de ellos y debe seguir utilizándolos cuando sean apropiados para describir o analizar un fenómeno determinado. El problema con las construcciones multidimensionales es que pueden ser variables independientes y dependientes problemáticas para analizar ciertos fenómenos.

Por ejemplo, si queremos investigar qué produce distintos niveles de prisión preventiva en diferentes jurisdicciones o países es insuficiente y hasta problemático decir que la causa principal del uso de la prisión preventiva es el sistema inquisitivo, dado 
que este sistema incluye múltiples rasgos procesales. ¿Es la existencia de jueces de instrucción, el uso de expedientes, la falta de audiencias durante la investigación preliminar, las disposiciones legales específicas sobre la libertad durante el proceso, o la ausencia de declaraciones de culpabilidad del acusado que disponen de la fase de juzgamiento, las que determinan los distintos niveles de prisión preventiva en diferentes jurisdicciones? ¿Son todas estas variables, solo algunas de ellas o ninguna de ellas las que afectan los niveles de prisión preventiva? Si agregamos todas estas variables en un modelo multidimensional inquisitivo, no es posible contestar estas preguntas de modo riguroso y persuasivo.

O supongamos que queremos estudiar si determinadas características específicas del proceso penal en un conjunto de países tienen efecto respecto a la clase de imputados contra los cuales estos países inician procesos judiciales por crímenes internacionales con base en la jurisdicción universal (definidos en un espectro continuo de individuos políticamente poderosos o débiles). Si describimos al proceso penal en cuestión utilizando modelos multidimensionales puede ser imposible saber cuáles características del proceso penal tienen efecto respecto a la clase de imputados contra los que se inician los procesos judiciales. ¿Se pueden explicar los diversos patrones de persecución penal en distintos países por diferencias en el grado de discrecionalidad fiscal para ejercer la persecución penal, por las reglas probatorias que tienen estos países, por la posibilidad de que la víctima sea parte en el proceso penal, o por ninguna de ellas? A menos que identifiquemos y analicemos cada variable individual por separado, será imposible responder a estas preguntas adecuadamente. ${ }^{78}$

La segunda cuestión a tener en cuenta es si el derecho procesal penal comparado debería relacionarse con una gama más extensa de disciplinas teóricas, a fin de ampliar y trascender los temas principales que ha estudiado. En este sentido, para superar su concentración predominante en los países desarrollados de Occidente y su relativa falta de interés en el modo en que el proceso penal afecta a la persecución transnacional del delito, el derecho procesal penal comparado podría relacionarse más profundamente y utilizar más herramientas y perspectivas de las literaturas sobre la globalización del derecho, las relaciones internacionales y los estudios sobre postcolonialismo, por mencionar solo tres posibles ejemplos. ${ }^{79}$

Para ampliar y trascender su análisis de derecho positivo e institucional, el derecho procesal penal comparado podría relacionarse más profundamente con las literaturas sobre derecho y economía, ciencias políticas, criminología y sociología. Por ejemplo, y siguiendo las tradiciones teóricas descritas en las secciones previas, el derecho procesal

\footnotetext{
78 Por este motivo no utilicé las categorías acusatorio-inquisitivo u otros modelos multidimensionales similares como variables independientes en Langer (2011), en donde sostengo que el grado de control del poder ejecutivo sobre la decisión de iniciar o no formalmente un proceso ha influido en el tipo de acusados contra los cuales estos procesos han sido iniciados.

79 Para intentos de análisis comparados del procesal penal para relacionarse con y utilizar herramientas y perspectivas de estas literaturas, ver Langer (2004; 2007; y 2011).
} 
penal comparado ha analizado si efectivamente y de qué manera, las normas institucionales acusatorias e inquisitivas han moldeado la discrecionalidad en la persecución penal y cómo los fiscales han ejercido esa discrecionalidad en distintas jurisdicciones. ${ }^{80}$ Un buen número de estudios de derecho y economía y ciencias políticas más bien tenderían a concentrarse en la estructura de incentivos que tienen las legislaturas, los poderes ejecutivos y los jueces para otorgar discrecionalidad a los fiscales, así como en los incentivos de los propios fiscales para ejercer esa discrecionalidad de un modo concreto. ${ }^{81} \mathrm{~A}$ fin de trascender su propia visión institucional predominante, los análisis comparados del procesal penal podrían relacionarse más profundamente con la criminología y la sociología que se focalizan en quiénes son los "clientes" de las instituciones públicas, y el modo en que las cuestiones de clase, raza, etnia, género, edad y estatus migratorio inciden en el funcionamiento del proceso penal. Vale la pena repetir una vez más que la idea no es que los análisis comparados del proceso penal abandonen completa o sustancialmente sus perspectivas preexistentes, sino que complementen estas perspectivas con otras que pueden enriquecer aún más nuestro conocimiento y análisis del proceso penal.

El tercer tema que merece consideración es de índole metodológica. El derecho procesal penal comparado ha sido muy sólido en la producción de estudios con base en el análisis jurídico, la investigación histórica de archivo, entrevistas con los operadores del sistema de justicia penal y la observación directa de las prácticas judiciales. ${ }^{82}$ Sin embargo, ha hecho muy poco en término de métodos cuantitativos. ${ }^{83}$ Nuevamente, no se trata de descartar toda metodología empírica que no sea cuantitativa y no utilice regresiones multivariables, tal como han hecho ciertas vertientes de otras disciplinas. Por el contrario, la idea es expandir el conjunto de herramientas metodológicas y abordajes de modo tal que los estudios cuantitativos sean un complemento de aquellos cualitativos. ${ }^{84}$

En el plano normativo es importante que distingamos entre la forma y la sustancia. Los sistemas acusatorio e inquisitivo son dos formas de implementar los principios y fines del proceso penal, pero no deberían ser confundidos con aquellos. En vez de comenzar por preguntarnos cuál de los sistemas es normativamente superior al otro, convendría plantearnos cuáles deberían ser los principios y fines del proceso penal, y luego discutir cuál sería la mejor forma de implementarlos en jurisdicciones específicas. Si bien han existido algunos intentos por encauzar la discusión de esta manera, estos intentos todavía son incipientes y muy pocos. ${ }^{85}$

80 Ver, p. ej., Abraham S. Goldstein y Martin Marcus (1977), Langbein y Weinreb (1978).

81 Para análisis comparados del comportamiento de los fiscales con base en sus incentivos, ver Garoupa (2012), Langer (2011).

82 Ver, p. ej., Hodgson (2005), Johnson (2001), Langbein (2003), Langer (2007).

83 Una rara excepción: Feeney (1998).

84 Para un intento de integrar los métodos cuantitativo y cualitativo con modelos del derecho procesal penal comparado, ver Langer y Doherty (2011).

85 Ver Duff, Farmer, Marshall y Tadros (2007), Ferrajoli (2009), Jackson (2005), Jackson y Summers (2012), Roberts (2006). 


\section{CONCLUSIÓN}

En este trabajo he analizado las categorías acusatorio-inquisitivo a fin de indagar sobre el estado actual del derecho procesal penal comparado, no solo como disciplina de investigación y análisis, sino también como espacio de pensamiento y de reforma sobre el proceso penal. En forma somera, describí algunos de los conocimientos y perspectivas que esta disciplina, campo de pensamiento y reforma han producido, así como también las limitaciones teóricas y temáticas que presentan. Estas limitaciones han sido parcialmente reflejadas y producidas por las categorías acusatorio-inquisitivo. Por ende, para que el derecho procesal penal comparado expanda sus horizontes debe trascender las categorías acusatorio-inquisitivo sin dejar de lado ni olvidar todo lo que estas categorías y su larga sombra nos han permitido ver y hacer.

\section{Referencias}

AMBOS, K.; GÓMEZ, J. L.; VOGLER, R. (Edits.). La policía en los estados de derecho latinoamericanos: un proyecto internacional de investigación. Bogotá D. C.: Ediciones Jurídicas Gustavo Ibáñez, 2003.

AMODIO, E.; SELVAGGI, E. An Accusatorial System in a Civil Law Country: The 1988 Italian Code of Criminal Procedure. Temple Law Review, 62 (4), 1211-1224, Invierno de 1989.

AVIRAM, H. Packer in Context: Formalism and Fairness in the Due Process Model. Law E Social Inquiry, 36(1),237-261, Invierno de 2011.

BRADLEY, C. M. (Ed.). Criminal procedure. A Worldwide Study (Segunda ed.). Durham, North Carolina: Carolina Academic Press, 2007.

BAYLEY, D. Patterns of policing. New Brunswick, New Jersey: Rutgers University Press, 1990.

. Changing the guard. Developing democratic police abroad. New York: Oxford University Press, 2006.

BINDER, A. Justicia penal y estado de derecho. Buenos Aires: Editorial Ad-Hoc, 1993.

CHIFFOLEAU, J. Avouer l'inavouable: l'aveau et la procédure inquisitoire à la fin du Moyen Âge. In: DULONG, R. L'Aveu: Histoire, sociologie, philosophie . Paris: Droit et justice, 2001.p. 57-98.

DAMAŠKA, M. Evidentiary barriers to conviction and two models of criminal procedure: a comparative study. Pennsylvania: University of Pennsylvania Law Review, 1973.

. The death of legal torture. New Haven, Connecticut: Yale Law Journal, 1978.

. Adversary System. In: KADISH, S. (Ed.) The encyclopedia of crime and justice. New York: The Free Press, 1984. p. 24 ss. 
DAMAŠKA, M. The faces of justice and state authority: A comparative approach to the legal process. New Haven: Yale University Press, 1986.

. Atomistic and Holistic Evaluation of Evidence. A Comparative View. In: CLARK, D. (Ed.) Comparative and Private International Law. Essays in honor of John Merryman on his seventieth birthday. Berlin: Duncker \& Humblot, 1990.

. Evidence law adrift. New Haven: Yale University Press, 1997.

. Truth in Adjudication. Hastings Law Journal. San Francisco: University of California, 49, 288-308, 1998.

. Models of Criminal Procedure. Zbornik (Collected Papers of Zagreb Law School). Zagreb: University of Zagreb Law School, 51, 477 y ss, 2001.

. The Quest for Due Process in the Age of Inquisition. American Journal of Comparative Law. Michigan: Universidad de Michigan, 60(4), 919-954, 2012.

DELMAS-MARTY, M.; SPENCER, J. R. (Edits.). European Criminal Procedures. Cambridge: Cambridge University Press, 2002.

DUBBER, M. D. The German Jury and the Metaphysical Volk: From Romantic Idealism to Nazi Ideology. American Journal of Comparative Law, 43(2), 227-272, (Primavera de 1995).

DUFF, A.; FARMER, L.; MARSHALL, S.; TADROS, V. (Edits.). The trial on trial. Portland. Oregon: Hard Publishing, 2007.

ELLISON, L. The Protection of Vulnerable Witnesses: an Anglo-Dutch Comparison. International journal of evidence and proof, 3, 29-43, 1993.

ESMEIN, A. Histoire de la procedure criminelle en france. Paris: L. Larose et Forcel Libraires-Éditeurs, 1882.

FEENEY, F. F. German and American prosecutions: an approach to statistical comparison. California: Bureau of Justice Statistics, U.S. Department of Justice, 1998.

FELDMAN, D. England and Wales. In: BRADLEY, C. M. (Ed.) Criminal procedure. a worldwide study. Durham: Carolina Academic Press, 2007. p. 149-196.

FERRAJOLI, L. Diritto e raggione. Teoria del garantismo penale. 10. ed. Roma: Editori Laterza, 2009.

FIELD, S. State, Citizen, and Character in French Criminal Process. Journal of Law and Society, 33(4), 522-546, Diciembre 2006.

FRASE, R. S. Comparative Criminal Justice as a Guide to American Law Reform: How Do the French Do it, How Can We Find Out, and Why Should We Care? California Law Review, 78, 545-682, Mayo 1990.

; WEIGEND, T. German Criminal Justice as a Guide to American Law Reform: Similar Problems, Better Solutions? Boston College International and Comparative Law Review, 18(2), 317-360, Ago. 1995. 
GANE, C. H. W. Classifying Scottish Criminal Procedure. In: DUFF, P.; HUTTON, N. (Edits.) Criminal Justice in Scotland. London: Dartmouth Publishing Co Ltd., 1999. p. 56 ss.

GARAPON, A.; PAPADOPOULOS, J. Juger en Amérique et en France: culture juridique française et common law. Paris: Editions Odile Jacob, 2003.

GAROUPA, N. M. The Economics of Prosecutors. In: HAREL, A.; HYLTON, K. N. (Edits.) Research handbook on the economics of criminal law. Northampton, Massachusetts: Edward Elgar Publishing Ltd., 2012. p. 231-242.

GARRAUD, R. Traité théorique et pratique d'instruction criminelle et de procédure pénale. Paris: Librairie de la Société du Recueil J.-B. Sirey \& du Journal du Palais, 1907, v. 1.

GOLDBACH, T. S.; BRAKE, B.; KATZENSTEIN, P. J. The Movement of U.S. Criminal and Administrative Law: Processes of Transplanting and Translating. Indiana Journal of Global Legal Studies, 20, 141 y ss, Enero 2013.

GOLDSTEIN, A. S. Reflections on Two Models: Inquisitorial Themes in American Criminal Procedure. Stanford Law Review, 26(5), 1009-1025, Mayo 1974.

; MARCUS, M. The Myth of Judicial Supervision in Three 'Inquisitorial' Systems: France, Italy, and Germany. The Yale Law Journal, 87, 1549-1569, Julio 1978.

GRANDE, E. Comparative Criminal Justice. In: BUSANI, M.; MATTEI, U. (Edits.) The Cambridge companion to comparative law. New York: Cambridge University Press, Oct. 2012, p. 191 ss.

. Italian Criminal Justice: Borrowing and Resistance. American Journal of Comparative Law, 48, 227-260, 2000.

GRAY, C. M. et al. Even. The privilege against self-incrimination. Its origins and development. Chicago: University of Chicago Press, 1997.

GRIFFITHS, J. Ideology in Criminal Procedure or A Third "Model” of the Criminal Process. The Yale Law Journal, 79(3), 359-417, Mar. 1970.

H. An Account of the Criminal Law, Criminal Courts, and Criminal Procedure of Germany; With Notices of the Principal Writers on Penal Jurisprudence, and the Principle Theories of Penal Legislation Prevailing There. Law Magazine Quarterly Review of Jurisprudence, 11, 1, 1834.

HÉLIE, F. Traité de l'instruction criminelle: ou théorie du Code d'instruction criminelle. Paris: Charles Hingray, Linraire-Éditeur, 1855. v. V.

HELMOLZ, R. H. et al. The privilege against self-incrimination. Its origins and development. Chicago: University of Chicago Press, 1997.

HERMANN, J. Various Models of Criminal Proceedings. South African Journal of Criminal Law and Criminology,2(1), 3-19, 1978.

HODGSON, J. French criminal justice. A comparative account of investigation and prosecution of crime in France. Portland, Oregon: Hart Publishing, 2005. 
IONTCHEVA TURNER, J. Judicial Participation in Plea Negotiations: A Comparative View. American Journal of Comparative Law, 94, 501-568, Junio 2006.

JACKSON, J. D. The Effect of Human Rights on Criminal Evidentiary Processes: Convergence, Divergence or Realignment? Modern Law Review, 68(5), 737-764, Sept. 2005.

; LANGER, M.; TILLERS, P. (Comps.). Crime, procedure and evidence in a comparative context: essays in honor to Mirjan Damaška. Oxford: Hart Publishing, 2008.

; SUMMERS, S. J. The Internationalization of criminal evidence. Beyond the common law and civil law traditions. Cambridge: Cambridge University Press, 2012.

JOHNSON, D. T. The Japanese way of justice. Prosecuting Crime in Japan. New York: Oxford University Press, 2001.

JÖRG, N.; FIELD, S.; BRANTS, C. Are Inquisitorial and Adversarial Systems Converging? In: FENNELL, P. et al. (Comps.) Criminal justice in Europe. Oxford: Clarendon Press, 1995.

KAGAN, R. A. Adversarial legalism: The american way of the law. Cambridge, Massachusetts: Harvard University Press, 2003.

KEITNER, C. Rights Beyond Borders. Yale Journal of International Law, 36, 55-114, Dic. 14 de 2010.

KÉRY, L. Inquisitio - denunciato - exception: Möglichkeiten der Verfahrenseinleitung im Dekretalenrecht. In: Zeitschrift der Savigny-Stiftung für Rechtsgeschichte. Weimar: Böhlau, 2004. p. 226 ss.

LACEY, N.; ZEDNER, L. Community in German Criminal Justice: A Significant Absence? Social \& Legal Studies, 7(1), 7-25, Mar. 1998.

LANGBEIN, J. Torture and the law of proof. Chicago: University of Chicago Press, 1976.

. The criminal Trial Before the Lawyers. University of Chicago Law Review, 45(2), 263-316, 1978.

. Torture and Plea Bargaining. University of Chicago Law Review, 46, 3-22, 1978.

; WEINREB, L. L. Continental Criminal Procedure: 'Myth' and Reality. Yale Low Journal, 87(8), 1549-1569, Julio de 1978.

. Mixed Court and Jury Court: Could the Continental Alternative Fill the American Need? American Bar Foundation Research Journal, 195-219, Invierno de 1981.

. The Origins of Adversary Criminal Trial. Oxford: Oxford University Press, 2003.

LANGER, M. La dicotomía acusatorio-inquisitivo y la importación de mecanismos procesales de la tradición jurídica anglo-sajona. Algunas reflexiones a partir del procedimiento abreviado. In: MAIER, J.; BOVINO, A. (Comps.) Procedimiento Abreviado. Buenos Aires: Editores del Puerto, 2001. p. 97-135. 
LANGER, M. From Legal Transplants to Legal Translations: The Globalization of Plea Bargaining and the Americanization Thesis in Criminal Procedure. Harvard International Law Journal, 45(1), 1-64, Enero de 2004.

. The Rise of Managerial Judging in International Criminal Law. American Journal of Comparative Law, 53(4), 835-909, Otoño de 2005.

. Rethinking Plea Bargaining: The Practice and Reform of Prosecutorial Adjudication in American Criminal Procedure. American Journal of Criminal Law, 33, 223 ss, Julio de 2006.

. Revolution in Latin American Criminal Procedure: Diffusion of Legal Ideas from the Periphery.American Journal of Comparative Law, 55, 617-676, 2007.

. The Diplomacy of Universal Jurisdiction: The Political Branches and the Transnational Prosecution of International Crimes. American Journal of International Law, 105(1), 1-49, 2011.

; JACKSON, J.; TILLERS, P. (Edits.). Crime, procedure and evidence in a comparative and international context. Essays in honor of professor Mirjan Damaška. Oxford: Hart Publishing, 2008.

; DOHERTY, J. W. Managerial Judging Goes International, but its Promise Remains Unfulfilled: An Empirical Assessment of the ICTY Reforms. Yale Journal of International Law, 36(2), 241-305, 2011.

; ROACH, K. Rights in the criminal process: a case study of convergence and disclosure rights. In: TUSHNET, M.; FLEINER, T.; SAUNDERS, C. (Edits.) Routlegde Handbook on Constitutional Law. Abingdon, Oxon; New York, NY: Routledge, Octubre 11 de 2013. p. 273-283.

LOTTE K. Inquisitio - denunciato - exception: Möglichkeiten der Verfahrenseinleitung im Dekretalenrecht. In: Zeitschrift der Savigny-Stiftung für Rechtsgeschichte. Weimar: H. Boöhlau, 2001. p. 226-268.

LUBAN, D. Lawyers and Justice: an ethical study. Princeton, Nueva Jersey: Princeton University Press, 1988.

LUNA, E. A Place for Comparative Criminal Procedure. Brandeis Law Journal, 42, 277 ss, Invierno de 2004.

; WADE, M. (Edits.). The prosecutor in transnational perspective. New York: Oxford University Press, 2012.

MAIER, J. Derecho procesal penal. 2. ed. Buenos Aires: Editores del Puerto, 1996.

MACLEOD, A. Exporting U.S. Criminal Justice. Yale Law \& Policy Review, 29, 83 ss, 2010.

MARKOVITS, I. Playing the Opposite Game: On Mirjan Damaška's The Faces of Justice and State Authority. Stanford Law Review, 41, 1313 ss, 1989. 
MENKEL-MEADOW, C. The Trouble with the Adversary System in a Postmodern, Multicultural World. William \& Mary Law Review, 38, 5-44, 1996.

MINISTÈRE DE LA JUSTICE, Commission Justice Pénale et Droits de L'homme. La Mise en État des Affaires Pénales. Paris, 1991.

MITTERMAIER, K. Das deutsche Strafverfahren. Heidelberg: Mohr, 1832.

. Lehre vom Beweise im deutschen Strafprozesse. Darmstadt: J. W. Heyer, 1834.

. Theorie des Beweises im peinlichen Prozesse. Darmstadt: Johann Wilhelm Heyer, 1809.

MORGAN, E. M. Some Observations Concerning Presumptions. Harvard Law Review, 44(6), 906-934, Abril de 1931.

NELKEN, D. (Ed.). Comparing legal cultures. Hanover, Nuevo Hampshire: Dartmouth Pub Co., 1997.

. Contrasting criminal justice. Farnham, Surrey, United Kingdom: Ashgate Publishing, 2000.

. Comparative criminal justice: making sense of difference. Los Ángeles: Sage Publications, 2010.

SHERIDAN, C. Excluding Coerced Witness Testimony to Protect a Criminal Defendant's Right to Due Process of Law and Adequately Deter Policy Misconduct.Fordham Urban Law Journal, 38, 1221-1266, 2011.

PACKER, H. L. Two Models of Criminal Procedure. University of Pennsylvania Law Review. 113(1), 1-68, Noviembre de 1964.

PADOA SCHIOPPA, A. I Philosophes e la Giuria Penale. Nuova Rivista Storica, LXX, 107146, 1986.

PASHUKANIS, E. Selected Writings on Marxism and Law (P. B. Maggs, Trad.). London: Academic Press Inc., 1980.

PENNINGTON, K. The prince and the law, 1200-1600: Sovereignty and rights in the western legal tradition. California: University of California Press, 1993.

. The Jurisprudence of Procedure. In: HARTMANN, W.; PENNINGTON, K. (Edits.) The history of courts and procedure in medieval canon law (en prensa), 2014.

PIZZI, W. T. Understanding Prosecutorial Discretion in the United States: The Limits of Comparative Criminal Procedure as an Instrument of Reform. Ohio State Law Journal, 54, 1325-1373, Otoño de 1993.

. Trials without truth. New York: New York University Press, 1999.

POSNER, R. A. An Economic Approach to the Law of Evidence. Stanford Law Review, 51(6), 1477-1546, Julio de 1999.

RASSAT, M. Procédure pénale. Paris: Ellypses Édition Marketing, 2010. 
$\mathrm{ROACH}, \mathrm{K}$. Four Models of the Criminal Process. Journal of Criminal Law \& Criminology, 89(2), 671-7162010, Invierno de 1999.

Wrongful Convictions: Adversarial and Inquisitorial Themes. North Carolina Journal of International Law and Commercial Regulation, 35, 387-446, Junio de 2010.

ROBERTS, P. On Method: The Ascent of Comparative Criminal Justice. Oxford Journal of Legal Studies, 22, 539-561, 2002.

. Theorising Procedural Traditional: Subjects, Objects and Values in Criminal Adjudication. En The Trial on Trial. Oxford: Hart Publishing, 2006. p. 37-64.

; HUNTER, J. (Edits.) Criminal evidence and human rights. Portland, Or.: Hart Publishing, 2012.

ROSS, J. E. The Place of Covert Surveillance in Democratic Societies: A Comparative Study of the United States and Germany. American Journal of Comparative Law, 55, 493579, Verano de 2007.

SCHÜNEMANN, B. Der Richter im Strafverfahren als manipolierter Dritter? - Zur empirischen Bestätigung von Perserveranz - und Schulterschlußeffekt. In: BIERBRAUER, Günther; GOTTWALD, Walter; BIRNBREIER-STAHLBERGER, Beatrix (Comps.). Verfahrensgerechtigkeit. Rechtspsychologische Forschungsbeiträge für die Justizpraxis, 1995. p. $215 \mathrm{ss})$.

. Zur Kritik des amerikanischen Strafprozessmodells. In: WESSLAU, Edda; WOHLERS, Wolfgang (Comps.). Festschrift für Gerhard Fezer. Berlin: De Gruyter Recht, 2008. p. 555-576.

SHAPIRO, M. Courts. A comparative and political analysis. Chicago: University of Chicago Press, 1981.

SHERIDAN, K. Excluding Coerced Witness Testimony to Protect a Criminal Defendant's Right to Due Process of Law and Adequately Deter Policy Misconduct. Fordham Urban Law Journal, 38(4), 1219-1266, 2010.

SKLANSKY, D. A. Anti-Inquisitorialism. Harvard Law Review, 122, 1634-1704, 2008.

SUMMERS, S. Fair Trials. The European criminal procedure tradition and the European court of human rights. Portland, Oregon: Hart Publishing, 2007.

THAMAN, S. Comparative criminal procedure: a casebook approach. 2. ed. Durham, North Caroline: Carolina Academic Press, 2008.

VAN KESSEL, G. European Perspectives on the Accused as a Source of Testimonial Evidence. West Virginia Law Review, 100, 799 ss, 1998.

VAN KOPPEN, P. J.; PENROD, S. D. (Edits.). Adversarial versus inquisitorial justice: psychological perspectives on criminal justice systems. New York, London: Kluwer Academic/Plenum Publishers, 2003.

VOGLER, R. A world view of criminal justice. Aldershot [u.a.]: Ashgate, 2005. 
WEIGEND, T. Should We Search for the Truth, and Who Should Do It? North Carolina Journal of International Law and Commercial Regulation, 36, 389-414, Invierno de 2011.

WEINREB, L. L. Denial of justice: criminal process in the United States. New York: Free Press, 1977.

WHITMAN, J. Q. The Two Western Cultures of Privacy: Dignity versus Liberty. Yale Law Journal, 113, 1151-1221, Abril de 2004.

Equality in Criminal Law: The Two Divergent Western Roads. Journal of Legal Analysis, 1 (1), 119-165, Enero de 2009.

ZWEIGERT, K.; KÖTZ, H. An introduction to comparative law. 3. ed. (T. Weir, Trad.) Oxford: Oxford University Press, 1998.

\section{Casos}

Colorado v. Connelly (1986) 479 U.S. 157.

Fitt v. United Kingdom (29777/96), (2000) 30 E.H.R.R. 480, $\$ 44$.

Kennedy v. United Kingdom (26839/05), (2011) 52 E.H.R.R. 4, $\$ 184$.

Kostovski v. The Netherlands (11454/85), (1989) 12 E.H.R.R. 434, $\$ 41$.

Rogers v. Richmond, (1961) 365 U.S. 534, 81 S.Ct. 735, 5 L.Ed.2d 760.

Rowe and Davis v. the United Kingdom [GC], no 28901/95, ECHR 2000-II, $\$ 60$. 